\title{
ANALISA QUANTITY TAKE-OFF DENGAN MENGGUNAKAN AUTODESK REVIT
}

\author{
Danny Laorent ${ }^{1}$, Paulus Nugraha², Januar Budiman³
}

\begin{abstract}
ABSTRAK: Quantity Take-Off merupakan salah satu upaya dari kontraktor dengan melakukan perhitungan volume, yang nantinya akan digunakan sebagai bahan untuk menyusun $\mathrm{BQ}$ dalam tender dan nantinya juga dijadikan bahan untuk melakukan procurement. Oleh sebab kontraktor yang dapat melakukan quantity take-off dengan akurat akan mendapatkan beberapa keuntungan seperti pengefisiensian material yang datang karena sesuai dengan aktual. Autodesk Revit merupakan sebuah tools atau aplikasi yang berbasis Building Information Modeling (BIM) yang mampu melakukan quantity take-off. Dalam penelitian ini akan dibahas bagaimana kelebihan dan kelemahan dari Autodek Revit dalam melakukan quantity take-off pada volume beton, bila dibandingkan dengan metode yang selama ini dipakai, yaitu menghitung volume dengan menggunakan gambar dari Autocad dan dengan bantuan Microsoft Excel. Hasil dari penelitian ini menunjukkan bahwa Autodesk Revit dapat melakukan quantity take-off dengan baik dan memiliki beberapa kelebihan seperti, memiliki efisiensi terhadap waktu karena dapat menghitung volume dengan lebih cepat dibandingkan dengan metode sebelumnya, apalagi bila terdapat perubahan desain. Akan tetapi dalam membuat permodelan pada Revit membutuhkan waktu yang cukup lama dan harus teliti agar memperoleh hasil yang akurat.
\end{abstract}

Kata Kunci : quantity take-off, building information modeling, autodesk revit

ABSTRACT: Quantity Take-Off is one of the efforts of contractors to make calculations volume, which will be used as the object for making Bill of Quantity in the tender and will also be made to make procurement. Therefore contractors who can do quantity take-off accurately will get some advantages such as efficiency material that came as it was in accordance with the actual. Autodesk Revit is a tools or application based on Building Information Modeling (BIM) which is capable of performing quantity take-off. In this research will be discussed how advantages and deficiency of Autodek Revit in quantity take-off to calculate concrete volume, when compared with the method that have been used, it is calculating volume using image from Autocad and help with Microsoft Excel. Result of this research showed that Autodesk Revit can do quantity take-off with good and has a number of advantages such as, have efficiency to the time because they can calculate volume with more rapidly than method before, especially if there is a redesign. But in making modeling in Revit takes a lot of time for a long time to have a careful and is to be accurate results.

Keyword: quantity take-off, building information modeling, autodesk revit

\footnotetext{
${ }_{1}^{1}$ Mahasiswa Program Studi Magister Teknik Sipil Universitas Kristen Petra, dannylaorent@gmail.com

2 Dosen Program Studi Magister Teknik Sipil Universitas Kristen Petra, pnugaraha@petra.ac.id

${ }^{3}$ Dosen Program Studi Magister Teknik Sipil Universitas Kristen Petra, jbn2500@gmail.com
} 


\section{PENDAHULUAN}

Dalam beberapa tahun terakhir ini perkembangan dunia konstruksi sangat meningkat dengan cukup pesat. Seiring pertumbuhan dunia kontruksi yang semakin berkembang maka para pelaku yang terlibat didalamnya, seperti owner, kontraktor maupun konsultan justru mencoba mencari jalan untuk melakukan efisiensi terhadap kegiatan-kegiatan yang terdapat didalamnya.

Salah satu cara yang dapat digunakan untuk melakukan efisiensi tersebut adalah menggunakan BIM (Building Information Modelling). BIM adalah suatu proses dalam menghasilkan dan mengelola data suatu bangunan selama life cycle-nya. Konsep BIM telah ada sejak tahun 1970-an, namun istilah Building Information Modelling pertama kali muncul dalam sebuah makalah 1992 oleh GA van Nederveen dan FP Tolman.

BIM melalui tools-nya Autodesk Revit telah digunakan untuk beberapa peneltian, seperti penelitian yang dilakukan oleh Rayendra \& Soemardi (2014) yaitu menggunakan Revit untuk memodelkan site layout dari sebuah proyek. Kemudian yang dilakukan oleh Sutanto (2015), melakukan perhitungan volume beton precast dengan menggunakan Revit.

Menurut Sunartyas (2015), salah seorang anggota dari IQSI (Ikatan Quantity Surveyor Indonesia) metode perhitungan volume di Indonesia sejauh ini masih berdasarkan dari gambar pada Autocad dan dibantu dengan Microsoft Excel dengan berpedoman pada SMM (Standard Method of Measurement). SMM merupakan pedoman atau aturan yang berisikan hal-hal dan penjelasan mengenai cara mengambil volume, menuliskan uraian dan menyusun pekerjaan bangunan. Standarisasi ini telah dimiliki oleh beberapa negara seperti Inggris, Australia, Selandia Baru, India, Hongkong, Singapura, Malaysia, dan beberapa negara persemakmuran lainnya, akan tetapi di Indonesia belum ada, sehingga masih sering menggunakan peraturan dari negara lain (Utama, 2009). Berdasarkan latar belakang masalah yang telah disebutkan diatas maka pada penelitian kali ini akan dilakukan analisa kelebihan dan kekurangan Autodesk Revit untuk melakukan quantity take-off. Alasan digunakannya software Autodesk Revit ini karena di Benua Asia, khususnya Indonesia sudah sangat mengenal dan banyak menggunakan Autocad, yaitu salah satu produk software dari perusahaan Autodesk juga. Oleh karena itu Autodesk Revit lebih mudah untuk diperkenalkan di Indonesia.

\section{TAHAPAN PENELITIAN}

Penelitian ini dimulai dengan pendahuluan untuk mencari latar belakang serta alasan penelitian ini dilakukan, yaitu perlunya mengetahui kelebihan dan kekurangan dari Autodesk Revit sebagai salah satu tools dari BIM agar dapat melakukan efisiensi dan mempermudah proses konstruksi. Kemudian mencari tinjauan pustaka mengenai permodelan dengan BIM, Autodesk Revit, quantity take-off, dan penelitian-penelitian sebelumnya dengan menggunakan Revit.

Selanjutnya akan dibuat permodelan untuk contoh kasus yang pertama dan dilanjutkan dengan contoh kasus yang kedua. Untuk contoh kasus yang pertama akan digunakan bangunan sederhana yang akan menjelaskan bagaimana cara Revit dalam memodelkan elemen struktur beton seperti balok, kolom, dan plat. Kemudian akan dibahas juga bagaimana kemampuan Revit dalam melakukan quantity take-off. Gambar 1 menunjukkan Gedung P1 \& P2 Universitas Kristen Petra Surabaya, dan bagian yang dilingkari yaitu Gedung P1-nya yang akan digunakan pada contoh kasus yang kedua. Untuk contoh kasus yang kedua akan dibahas kemampuan Revit melakukan quantity take-off pada volume beton dan akan dibandingkan dengan $\mathrm{BQ}$ dan perhitungan sendiri.

Kemudian akan dilanjutkan dengan analisa dan pembahasan dari contoh kasus yang pertama dan kedua, serta akan ditarik kesimpulan dan memberikan saran untuk penelitian selanjutnya. 


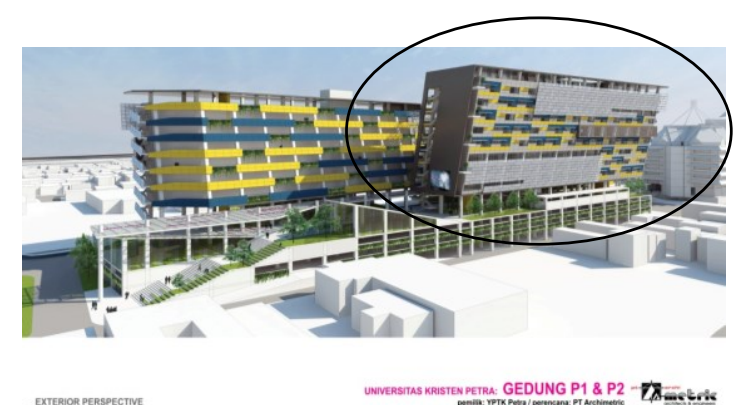

Gambar 1. Gedung P1 \& P2 Universitas Kristen Petra Surabaya

\section{HASIL PENELITIAN}

\section{Contoh Kasus 1}

Dalam contoh kasus 1 diberikan contoh permodelan sederhana yang nantinya akan dijelaskan bagaimana cara membuat permodelan dengan menggunakan Revit dan selanjutnya melakukan quantity take-off. Gambar 2 merupakan permodelan sederhana yang telah dibuat. Permodelan ini menggambarkan sebuah bangunan 2 lantai dengan elemen struktur seperti plat, kolom bundar, balok induk dan balok anak, serta terdapat balok diagonal. Langkahlangkah dalam membuat permodelan contoh kasus 1 :

1. Sebelum dilakukan penggambaran setiap elemen struktur perlu dibuat elevasi terlebih dahulu untuk memudahkan permodelan karena terdapat patokan yang digunakan.

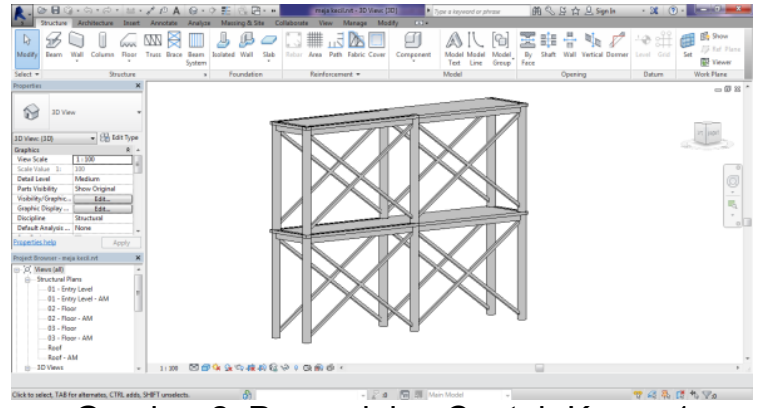

Gambar 2. Permodelan Contoh Kasus 1

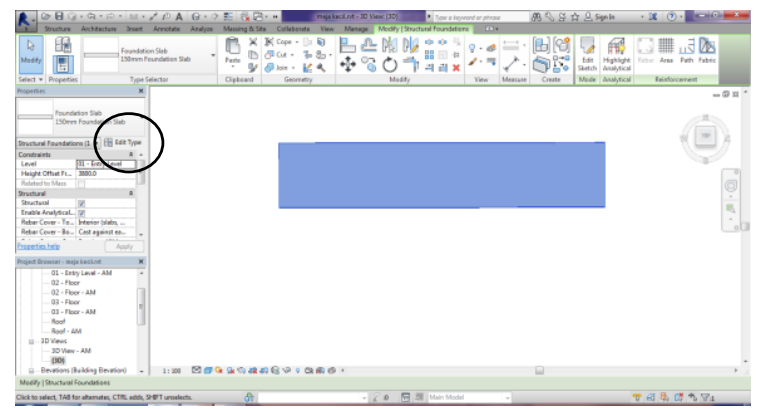

Gambar 3. Edit Type untuk Mengubah Tebal Plat

2. Elemen stuktur pertama yang akan dibuat adalah plat beton. Untuk penggambaran plat tersebut mirip dengan penggambaran pada Autocad. Pada contoh ini plat tersebut memiliki dimensi $10 \times 2$ meter dan tebal $10 \mathrm{~cm}$. Pertama memilih elemen plat, kemudian dilakukan penggambaran untuk dimensi panjang dan lebarnya menggunakan line seperti pada Autocad, selanjutnya menentukan tebal dari plat tersebut dengan memilih edit type (Gambar 3) baru mengubah tebal plat sesuai yang diinginkan, dalam contoh ini diambil tebal $10 \mathrm{~cm}$. Jangan lupa memperhatikan elevasi pada penggambaran plat, pengaturan elevasi tersebut dapat diatur pada bagian "level" yang terdapat pada properties dan diletakkan pada setiap elevasi yang diinginkan yang telah dibuat pada langkah sebelumnya.

3. Selanjutnya dilakukan pembuatan kolom, kolom yang digunakan pada contoh ini adalah kolom bundar dengan tinggi $3.8 \mathrm{~m}$ dan memiliki diameter $30 \mathrm{~cm}$. Pertama memilih elemen struktur kolom pada window tasks stucture, kemudian menentukan diameter kolom menggunakan edit type yang sama dengan langkah pada saat menentukan tebal plat (Gambar 3), mengubah diameter sesuai dengan yang diinginkan, dan selanjutnya menempatkan kolom tersebut pada area atau posisi yang telah ditentukan, dan terakhir memposisikan kolom tersebut sesuai dengan elevasi yang ditentukan. Untuk pengaturan elevasi perlu diperhatikan karena berbeda dengan plat, pada kolom harus mengisi elevasi pada base level dan top level-nya agar kolom tersebut berada pada elevasi yang diinginkan. Setelah satu kolom sudah dibuat, maka untuk yang lainnya tinggal di copy. 
4. Untuk penggambar elemen struktur balok dimulai dengan memilih elemen beam pada window tasks stucture, kemudian memilih ukuran $\mathrm{b}$ dan $\mathrm{h}$ yang diinginkan pada edit type seperti Gambar 3 pada saat penggambaran plat, dan selanjutnya menentukan ukuran b dan $h$ yang diinginkan. Selanjutnya penggambaran balok dapat dilakukan dengan menentukan titik awal dan titik akhir untuk menghasilkan panjang bentang yang diperlukan. Untuk penggambaran balok ini Revit memiliki kelebihan, yaitu meskipun memilih titik awal dan akhir bentang pada as elemen stuktur / dalam contoh ini yaitu tengah kolom bundar, hasil dari balok tersebut tetap menghasilkan bentang bersih tanpa ada yang masuk kedalam kolom tersebut. Elemen balok pada permodelan ini memiliki 3 jenis ukuran, yang pertama untuk balok induk memiliki dimensi $15 \times 30 \mathrm{~cm}$, balok anak $10 \times 20 \mathrm{~cm}$, dan balok diagonal $10 \times 10 \mathrm{~cm}$.

Tabel 1. Tabel Perbandingan Volume Contoh Kasus 1

\begin{tabular}{|l|c|c|}
\hline Item & Volume Revit $\left(\mathrm{m}^{3}\right)$ & Volume Perhitungan Sendiri $\left(\mathrm{m}^{3}\right)$ \\
\hline Kolom & 3.24 & 3.222 \\
\hline Balok & 2.74 & 2.98 \\
\hline Plat & 4 & 3.182 \\
\hline
\end{tabular}

Dapat dilihat pada Tabel 1 diatas, seluruh data volume hasil dari Revit untuk setiap elemen struktur telah direkap dan ditabelkan menjadi satu, kemudian dibandingkan dengan hasil perhitungan sendiri dan dilakukan analisa :

1. Untuk elemen kolomnya praktis tidak ada perbedaan yang signifikan atau dapat dikatakan sama, karena cara atau asumsi yang digunakan Revit untuk menghitung volume sama dengan asumsi dalam perhitungan sendiri. Untuk diameternya mengambil $30 \mathrm{~cm}$, kemudian tingginya mengambil bersih elevation to elevation yaitu 3.8 meter, dan jumlahnya total 12 buah, hanya mungkin terdapat perbedaan dalam pembulatan angka.

2. Kemudian untuk elemen baloknya terdapat sedikit perbedaan sekitar $0.2 \mathrm{~m}^{3}$. Pada dasarnya asumsi yang digunakan pada Revit sudah sama dengan perhitungan sendiri, yaitu "b" dikalikan dengan " $h$ " dan dikalikan bentang bersih untuk masing-masing balok. Akan tetapi terdapat perbedaan dalam mengambil bentang bersih, dalam perhitungan sendiri bentang bersih diambil dari panjang balok dari as kolom dikurangkan dengan setengah diameter kolom untuk setiap sisi. Tetapi karena dalam contoh ini karena kolomnya berbentuk bundar, maka perhitungan balok pada Revit lebih akurat karena bentang bersih dari balok mengikuti bentuk kolom bundar tersebut.

3. Untuk hasil perhitungan volume pada elemen struktur plat memiliki perbedaan yang cukup mencolok, hal ini dikarenakan perbedaan asumsi yang digunakan pada Revit dan perhitungan sendiri. Pada Revit langsung menghitung volume plat tersebut dengan dimensi 2x10 meter dikalikan dengan tebal $10 \mathrm{~cm}$ dan dikalikan 2 lantai, tanpa dikurangi oleh kolom dan balok yang volumenya telah dihitung sebelumnya. Sedangkan pada perhitungan sendiri volume plat yang dihitung dari mencari luasan plat bersih, yaitu luasan plat total 2x10 meter dikurangkan dengan luasan total kolom dan balok pada 1 lantai, baru dikalikan dengan tebalnya $10 \mathrm{~cm}$ dan selanjutnya dikalikan 2 lantai.

\section{Contoh Kasus 2 : Gedung P1 UKP}

Permodelan yang digunakan dalam penelitian ini adalah dengan menggunakan bangunan Universitas Kristen Petra Surabaya untuk bagian gedung P1-nya. Gedung Petra yang dimodelkan ini terdiri dari lantai semibasement, kemudian lantai 1 sampai dengan lantai 12 dan lantai atap, jadi total terdapat 14 lantai. Dengan tebal plat lantai yang berbeda-beda, lantai semibasement memiliki ketebalan $30 \mathrm{~cm}$, lantai 1 sampai dengan lantai 3 memiliki ketebalan $15 \mathrm{~cm}$, dan lantai 4 sampai dengan lantai atap memiliki ketebalan $12 \mathrm{~cm}$. Kemudian kolomnya memiliki ukuran mulai dari 400x800 cm sampai dengan 1x1 meter, dan terdapat shearwall 
berdimensi $600 \times 5000 \mathrm{~cm}$. Selanjutnya balok induknya memiliki ukuran $200 \times 350 \mathrm{~cm}$ sampai dengan $500 \times 900 \mathrm{~cm}$ dan balok anaknya memiliki ukuran $200 \times 300 \mathrm{~cm}$ sampai dengan $550 \times 800 \mathrm{~cm}$. Dari permodelan ini akan dicari volume beton yang terdapat pada bangunan tersebut mulai dari lantai semibasement sampai lantai dak atau lantai 13. Kemudian hasil volume yang didapat dari revit akan dibandingkan dengan hasil yang telah dihitung manual, dengan bantuan Autocad dan Microsoft Excel.

Permodelan dengan menggunakan Autodesk Revit dimulai dari :

1. Memasukkan gambar denah yang telah digambar 2D dari Autocad ke dalam Autodesk Revit. Dari Gambar 4 dapat dilihat pada awalnya gambar denah di import kedalam Autodesk Revit untuk memudahkan dalam permodelan.

2. Setelah gambar denah telah di import, maka selanjutnya dilakukan pembuatan grid atau As sebagai alat bantu untuk memplot elemen strukturnya (Gambar 5).

3. Kemudian dari gambar denah tersebut dibuat elemen-elemen strukturnya sesuai dengan posisi yang terdapat pada denah. Misal melakukan pembuatan kolom, maka terutama harus ditentukan terlebih dahulu berapa ukuran kolom yang ingin dibuat seperti pada Gambar 3, yaitu memilih edit type. Kemudian dapat dilihat pada Gambar 9, salah satu kolom di-plot sesuai dengan titik dan ukuran yang terdapat di denah. Cara tersebut dilakukan berulang kali pada setiap elemen struktur yang ada dan dilakukan pada setiap lantainya.
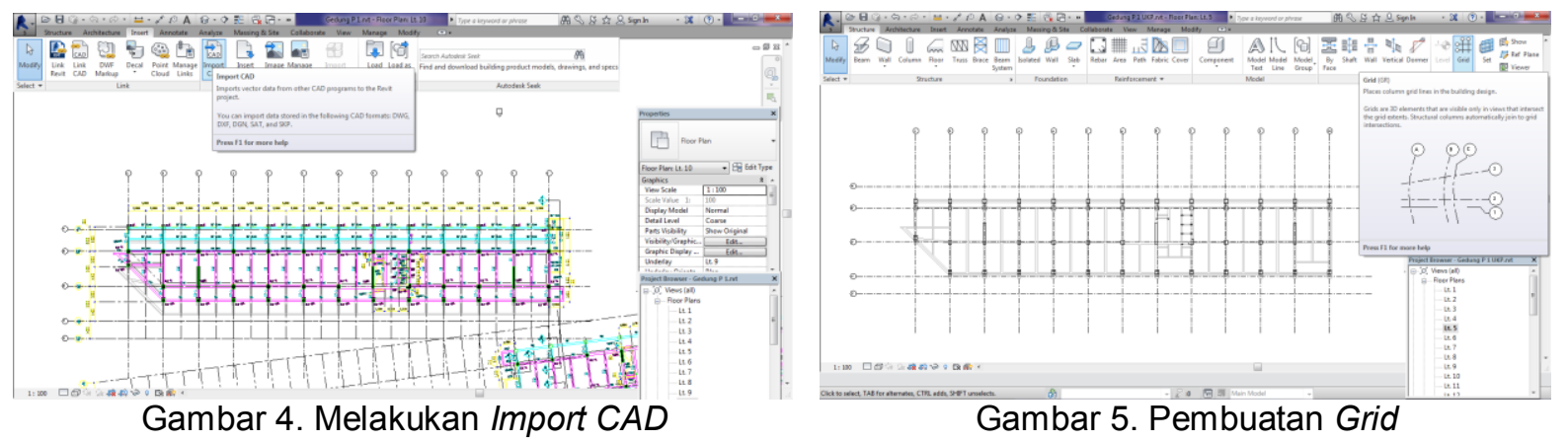

Gambar 5. Pembuatan Grid

Pada Tabel 2 dapat dilihat hasil seluruh volume beton yang didapatkan dengan menggunakan Revit dalam tampilan Microsoft Excel.

Tabel 2. Tabel Hasil Volume Beton dari Revit

\begin{tabular}{|l|c|c|c|}
\hline \multirow{2}{*}{ Lantai } & \multicolumn{3}{|c|}{ Volume Elemen Struktur (m3) } \\
\cline { 2 - 4 } & Plat & Kolom & Balok \\
\hline Lantai & & & \\
Semibasement & 741.13 & 210.81 & 85.67 \\
\hline Lantai 1 & 362.94 & 146.72 & 207.46 \\
\hline Lantai 2 & 351.38 & 147.38 & 163.07 \\
\hline Lantai 3 & 360.25 & 299.98 & 167.37 \\
\hline Lantai 4 & 186.504 & 181.26 & 173.8 \\
\hline Lantai 5 & 195.906 & 170.39 & 160.57 \\
\hline Lantai 6 & 195.904 & 170.49 & 158.03 \\
\hline Lantai 7 & 195.774 & 170.39 & 155.01 \\
\hline Lantai 8 & 203.672 & 170.39 & 164.7 \\
\hline Lantai 9 & 195.904 & 159.66 & 170.19 \\
\hline Lantai 10 & 195.904 & 159.66 & 160.43 \\
\hline Lantai 11 & 195.845 & 159.66 & 159.96 \\
\hline Lantai 12 & 196.207 & 127.63 & 109.88 \\
\hline Atap & 218.69 & - & 112.43 \\
\hline
\end{tabular}


Kemudian hasil dari perhitungan volume beton pada Autodesk Revit akan dibandingkan dengan perhitungan pada $B Q$ yang telah dibuat oleh kontraktor.

Pada Tabel 3, 4, dan 5 dapat dilihat bahwa perhitungan volume beton yang terdapat pada Autodesk Revit memiliki beberapa selisih dengan yang terdapat didalam $B Q$, yang dihitung dengan bantuan Autocad dan excel. Kemungkinan adanya selisih ini dapat disebabkan oleh perbedaan asumsi perhitungan volume antara $B Q$ dengan Revit, seperti kemungkinan adanya beberapa elemen yang dihitung dari as ke as sedangkan pada Revit menggunakan bentang bersih.

Tabel 3. Tabel Perbandingan Volume Beton pada Plat

\begin{tabular}{|l|c|c|c|}
\hline Lantai & $\begin{array}{c}\text { Volume dari } \\
\mathrm{BQ}\left(\mathrm{m}^{3}\right)\end{array}$ & $\begin{array}{c}\text { Volume dari } \\
\text { Revit }\left(\mathrm{m}^{3}\right)\end{array}$ & Selisih \\
\hline Lantai Semibasement & 742.50 & 741.13 & $0.2 \%$ \\
\hline Lantai 1 & 380.10 & 362.94 & $4.5 \%$ \\
\hline Lantai 2 & 360.60 & 351.38 & $2.6 \%$ \\
\hline Lantai 3 & 363.45 & 360.25 & $0.9 \%$ \\
\hline Lantai 4 & 188.80 & 186.504 & $1.2 \%$ \\
\hline Lantai 5 & 210.44 & 195.906 & $6.9 \%$ \\
\hline Lantai 6 & 200.42 & 195.904 & $2.3 \%$ \\
\hline Lantai 7 & 198.89 & 195.774 & $1.6 \%$ \\
\hline Lantai 8 & 200.56 & 203.672 & $1.6 \%$ \\
\hline Lantai 9 & 200.72 & 195.904 & $2.4 \%$ \\
\hline Lantai 10 & 198.90 & 195.904 & $1.5 \%$ \\
\hline Lantai 11 & 198.58 & 195.845 & $1.4 \%$ \\
\hline Lantai 12 & 191.39 & 196.207 & $2.5 \%$ \\
\hline Atap & 230.88 & 218.69 & $5.3 \%$ \\
\hline
\end{tabular}

Tabel 4. Tabel Perbandingan Volume Beton pada Balok

\begin{tabular}{|l|c|c|r|}
\hline Lantai & $\begin{array}{c}\text { Volume dari } \\
\mathrm{BQ}\left(\mathrm{m}^{3}\right)\end{array}$ & $\begin{array}{c}\text { Volume dari } \\
\text { Revit }\left(\mathrm{m}^{3}\right)\end{array}$ & Selisih \\
\hline Lantai Semibasement & 100.56 & 85.67 & $14.8 \%$ \\
\hline Lantai 1 & 260.78 & 207.46 & $20.4 \%$ \\
\hline Lantai 2 & 240.65 & 163.07 & $32.2 \%$ \\
\hline Lantai 3 & 238.70 & 167.37 & $29.9 \%$ \\
\hline Lantai 4 & 246.50 & 173.8 & $29.5 \%$ \\
\hline Lantai 5 & 220.43 & 160.57 & $27.2 \%$ \\
\hline Lantai 6 & 210.22 & 158.03 & $21.1 \%$ \\
\hline Lantai 7 & 200.22 & 155.01 & $22.6 \%$ \\
\hline Lantai 8 & 200.22 & 164.7 & $17.7 \%$ \\
\hline Lantai 9 & 198.87 & 170.19 & $14.4 \%$ \\
\hline Lantai 10 & 180.13 & 160.43 & $10.9 \%$ \\
\hline Lantai 11 & 170.22 & 159.96 & $6.0 \%$ \\
\hline Lantai 12 & 126.33 & 109.88 & $13.0 \%$ \\
\hline Atap & 142.01 & 112.43 & $20.8 \%$ \\
\hline
\end{tabular}

Tabel 5. Tabel Perbandingan Volume Beton pada Kolom

\begin{tabular}{|l|c|c|c|}
\hline Lantai & $\begin{array}{c}\text { Volume dari } \\
\mathrm{BQ}\left(\mathrm{m}^{3}\right)\end{array}$ & $\begin{array}{c}\text { Volume dari } \\
\text { Revit }\left(\mathrm{m}^{3}\right)\end{array}$ & Selisih \\
\hline Lantai Semibasement & 230.03 & 210.81 & $8.4 \%$ \\
\hline Lantai 1 & 160.80 & 146.72 & $8.8 \%$ \\
\hline Lantai 2 & 161.67 & 147.38 & $8.8 \%$ \\
\hline Lantai 3 & 310.45 & 299.98 & $3.4 \%$ \\
\hline Lantai 4 & 179.04 & 181.26 & $-1.2 \%$ \\
\hline Lantai 5 & 178.73 & 170.39 & $4.7 \%$ \\
\hline Lantai 6 & 177.89 & 170.49 & $4.2 \%$ \\
\hline Lantai 7 & 177.80 & 170.39 & $4.2 \%$ \\
\hline Lantai 8 & 176.32 & 170.39 & $3.4 \%$ \\
\hline Lantai 9 & 161.45 & 159.66 & $1.1 \%$ \\
\hline Lantai 10 & 160.76 & 159.66 & $0.7 \%$ \\
\hline Lantai 11 & 160.76 & 159.66 & $0.7 \%$ \\
\hline Lantai 12 & 133.42 & 127.63 & $4.3 \%$ \\
\hline
\end{tabular}

Selanjutnya dilakukan perhitungan volume beton dengan metode yang sebelumnya telah ada, yaitu dengan menggunakan Autocad dan bantuan Microsoft Excel untuk membandingkan kelebihan dan kekurangan dalam penggunaan Autodesk Revit sebagai metode untuk menghitung volume. Hasil perbandingan metode perhitungan tersebut dapat dilihat pada Tabel 6, 7, dan 8.

Dapat dilihat bahwa perhitungan volume beton yang terdapat pada Autodesk Revit memiliki beberapa selisih dengan yang perhitungan sendiri, yang dihitung dengan bantuan Autocad dan excel. Akan tetapi selisih yang didapat tidak sebesar apabila Revit dibandingkan dengan 
BQ. Hal ini disebabkan karena pada perhitungan sendiri penafsiran atau asumsi yang digunakan untuk melakukan perhitungan volume sama dengan yang digunakan pada Revit. Untuk kolom perhitungan volumenya menggunakan bentang elevation to elevation dikalikan dengan luasan permukaan masing-masing kolom. Kemudian untuk baloknya mengalikan dimensi ("b" dengan " $h$ ") dan dikalikan bentang bersih untuk masing-masing balok, karena tidak ada kolom bundar seperti pada contoh kasus 1, maka bentang bersih yang diambil sudah sama antara Revit dengan perhitungan sendiri. Selanjutnya untuk platnya, perhitungan sendiri pada contoh kasus ini berbeda dengan pada contoh kasus pertama, karena pada perhitungan kali ini mengikuti asumsi dari Revit, yaitu menghitung langsung seluruh area plat dikalikan dengan tebal masing-masing lantai, tanpa mengurangi luasan dari kolom dan balok, sehingga hasilnya tidak memiliki perbedaan yang signifikan.

Tabel 6. Tabel Perbandingan antara Perhitungan Sendiri dan Revit pada Pekerjaan Plat

\begin{tabular}{|l|c|c|c|}
\hline Lantai & $\begin{array}{c}\text { Volume dari } \\
\text { Perhitungan } \\
\text { Sendiri }\left(\mathrm{m}^{3}\right)\end{array}$ & $\begin{array}{c}\text { Volume } \\
\text { dari } \\
\text { Revit } \\
\left(\mathrm{m}^{3}\right)\end{array}$ & Selisih \\
\hline Lantai Semibasement & 732.10 & 741.13 & $-1.22 \%$ \\
\hline Lantai 1 & 366.02 & 362.94 & $0.85 \%$ \\
\hline Lantai 2 & 365.99 & 351.38 & $4.16 \%$ \\
\hline Lantai 3 & 365.85 & 360.25 & $1.55 \%$ \\
\hline Lantai 4 & 191.93 & 186.504 & $2.91 \%$ \\
\hline Lantai 5 & 197.44 & 195.906 & $0.78 \%$ \\
\hline Lantai 6 & 196.59 & 195.904 & $0.35 \%$ \\
\hline Lantai 7 & 196.59 & 195.774 & $0.42 \%$ \\
\hline Lantai 8 & 205.17 & 203.672 & $0.74 \%$ \\
\hline Lantai 9 & 200.22 & 195.904 & $2.20 \%$ \\
\hline Lantai 10 & 196.59 & 195.904 & $0.35 \%$ \\
\hline Lantai 11 & 196.53 & 195.845 & $0.35 \%$ \\
\hline Lantai 12 & 196.67 & 196.207 & $0.24 \%$ \\
\hline Atap & 225.37 & 218.69 & $3.05 \%$ \\
\hline
\end{tabular}

Tabel 7. Tabel Perbandingan antara Perhitungan Sendiri dan Revit pada Pekerjaan Balok

\begin{tabular}{|l|c|c|c|}
\hline Lantai & $\begin{array}{c}\text { Volume dari } \\
\text { Perhitungan } \\
\text { Sendiri }\left(\mathrm{m}^{3}\right)\end{array}$ & $\begin{array}{c}\text { Volume } \\
\text { dari } \\
\text { Revit } \\
\left(\mathrm{m}^{3}\right)\end{array}$ & Selisih \\
\hline Lantai Semibasement & 90.17 & 85.67 & $5.25 \%$ \\
\hline Lantai 1 & 210.22 & 207.46 & $1.33 \%$ \\
\hline Lantai 2 & 166.98 & 163.07 & $2.40 \%$ \\
\hline Lantai 3 & 170.34 & 167.37 & $1.77 \%$ \\
\hline Lantai 4 & 178.88 & 173.8 & $2.92 \%$ \\
\hline Lantai 5 & 162.44 & 160.57 & $1.16 \%$ \\
\hline Lantai 6 & 160.13 & 158.03 & $1.33 \%$ \\
\hline Lantai 7 & 160.56 & 155.01 & $3.58 \%$ \\
\hline Lantai 8 & 167.87 & 164.7 & $1.92 \%$ \\
\hline Lantai 9 & 175.68 & 170.19 & $3.23 \%$ \\
\hline Lantai 10 & 161.32 & 160.43 & $0.55 \%$ \\
\hline Lantai 11 & 161.72 & 159.96 & $1.10 \%$ \\
\hline Lantai 12 & 110.98 & 109.88 & $1.00 \%$ \\
\hline Atap & 115.86 & 112.43 & $3.05 \%$ \\
\hline \multicolumn{2}{|l|}{}
\end{tabular}

Tabel 8. Tabel Perbandingan antara Perhitungan

Sendiri dan Revit pada Pekerjaan Kolom

\begin{tabular}{|l|c|c|c|}
\hline Lantai & $\begin{array}{c}\text { Volume dari } \\
\text { Perhitungan } \\
\text { Sendiri }\left(\mathrm{m}^{3}\right)\end{array}$ & $\begin{array}{c}\text { Volume } \\
\text { dari } \\
\text { Revit } \\
\left(\mathrm{m}^{3}\right)\end{array}$ & Selisih \\
\hline Lantai Semibasement & 215.03 & 210.81 & $2.00 \%$ \\
\hline Lantai 1 & 147.90 & 146.72 & $0.80 \%$ \\
\hline Lantai 2 & 154.52 & 147.38 & $4.84 \%$ \\
\hline Lantai 3 & 300.64 & 299.98 & $0.22 \%$ \\
\hline Lantai 4 & 183.45 & 181.26 & $1.21 \%$ \\
\hline Lantai 5 & 172.70 & 170.39 & $1.36 \%$ \\
\hline Lantai 6 & 171.09 & 170.49 & $0.35 \%$ \\
\hline Lantai 7 & 171.20 & 170.39 & $0.48 \%$ \\
\hline Lantai 8 & 171.50 & 170.39 & $0.65 \%$ \\
\hline Lantai 9 & 159.90 & 159.66 & $0.15 \%$ \\
\hline Lantai 10 & 159.90 & 159.66 & $0.15 \%$ \\
\hline Lantai 11 & 159.88 & 159.66 & $0.14 \%$ \\
\hline Lantai 12 & 127.66 & 127.63 & $0.02 \%$ \\
\hline
\end{tabular}

\section{KESIMPULAN DAN SARAN}

Dari kedua contoh kasus diatas dapat disimpulkan bahwa Revit dapat digunakan sebagai tools untuk melakukan quantity take-off, karena memiliki kelebihan sebagai berikut: 
1. Revit dapat melakukan permodelan elemen struktur dengan baik dan mudah dipahami dalam penggunaannya, karena hampir sama dengan Autocad.

2. Perhitungan volume beton dari Revit memiliki hasil yang akurat pada elemen struktur kolom dan balok, karena pada kolom dihitung dengan menggunakan bentang elevation to elevation dan pada balok dihitung menggunakan bentang bersih sisi dalam kolom. Tetapi untuk elemen struktur plat, Revit langsung menghitung volume beton sesuai dengan permodelan plat yang digambar, tanpa mengurangi volume balok dan kolom yang ada didalamnya.

3. Dengan menggunakan Revit kemungkinan terjadi perbedaan penafsiran masing-masing pihak pada saat melakukan perhitungan volume dapat berkurang karena gambar permodelan yang dipakai sebagai dasar perhitungan volume hanya satu. Untuk proses perhitungannya memiliki waktu yang lebih cepat, karena setelah model tersebut dibuat maka volume dapat secara otomatis dihitung dan keluar. Apalagi ketika terdapat perubahan desain, maka hanya perlu mengubah gambar dan keluar volume yang baru, tidak perlu menghitung dari awal.

4. Dapat mengurangi atau meminimalkan kesalahan akibat human error karena apabila melakukan perhitungan volume dengan menggunakan Autocad dan Excel keterlibatan manusia dalam melakukan perhitungan cukup besar, sedangkan dengan menggunakan Revit dapat langsung mengetahui volume ketika model telah dibuat.

5. Dengan permodelan yang berbentuk 3D memudahkan banyak pihak untuk menganalisa dan mengkoreksi apabila terjadi perbedaan volume baik dari owner maupun kontraktor, sehingga mencegah terjadinya dispute.

Akan tetapi perlu diperhatikan beberapa hal yang mungkin dapat menjadi kelemahan dari Revit, yaitu :

1. Kemampuan atau skill dari pihak yang ingin menggunakan aplikasi Revit tersebut pada saat akan melakukan permodelan. Karena hal ini dapat menjadi titik lemah apabila model yang dibuat tidak sesuai dengan yang seharusnya, maka volume yang didapatkan-pun tidak dapat sesuai.

2. Kemudian untuk permodelannya membutuhkan waktu yang cukup lama dan harus teliti untuk menghasilkan perhitungan volume beton yang akurat.

Secara umum Autodesk Revit merupakan tools yang berbasis BIM yang dapat digunakan untuk membuat permodelan dan melakukan quantity take-off pada volume beton, namun diperlukan penyesuaian dan pengembangan lebih lanjut sebelum benar-benar dapat digunakan. Karena sangat diperlukan permodelan yang akurat dan teliti agar volume beton yang didapatkan sama dengan yang aktual.

Untuk pengembangan lebih lanjut disarankan menggunakan Autodesk Revit dalam menghitung volume pada bangunan yang memiliki struktur beton yang bervariatif. Selain itu disarankan juga untuk menggunakan Revit pada pekerjaan arsitektur.

\section{DAFTAR REFERENSI}

Soemardi, B. W., \& Rayendra. (2014). "Studi Aplikasi Teknologi Building Information Modeling untuk Pra-Konstruksi." Simposium Nasional RAPI XIII - 2014 FT UMS.

Sunartyas. (2015). Hasil Wawancara tanggal 22 Agustus 2015 di Pakuwon Indah.

Sutanto, H. (2015). "Exploiting The Use of BIM for Bid Preparation". Department of Civil \& Enviromental Engineering National University of Singapore.

Utama, W. P. (2009). "Standarisasi Pengukuran Kuantitas Pekerjaan Konstruksi di Indonesia : Suatu Gagasan". Fakultas Teknik Sipil dan Perencanaan Universitas Bung Hatta. $<$ http://webcache.googleusercontent.com/search?q=cache:mS0GJmARvjoJ: ftsp.bunghatta.ac.id/artikel-1standardisasi_pengukuran_kuantitas_pekerjaan konstruksi_di_indonesia_suatu_gagasan.html+\&cd=1\&hl=en\&ct=clnk\&gl=id > (2009). 